\title{
Influence of the Synchrotron Radiation on Particle Dynamics in a Rectangular Undulator
}

\author{
Yong Ho Chin
}

\author{
Accelerator and Fusion Research Division \\ Lawrence Berkeley Laboratory \\ 1 Cyclotron Road \\ Berkeley, California 94720
}

March 1989

\section{DISCLAIMER}

\begin{abstract}
This report was prepared as an account of work sponsored by an agency of the United States Government. Neither the United States Government nor any agency thereof, nor any of their employees, makes any warranty, express or implied, or assumes any legal liability or responsibility for the accuracy, completeness, or usefulness of any information, apparatus, product, or process disclosed, or represents that its use would not infringe privately owned rights. Reference hercin to any specific commercial product, process, or service by trade name, trademark, manufacturer, or otherwise does not necessarily constitute or imply its endorsement, recommendation, or favoring by the United States Government or any agency thereof. The views and opinions of authors expressed herein do not necessarily state or reflect those of the United States Government or any agency thereof.
\end{abstract}




\title{
INFLUENCE OF TIE SYNCI IROTRON RADLATION ON PARTICLE DYNAMICS IN A RECTANGULAR UNDULATOR*
}

\author{
Yong llo Chin \\ Lawrence Berkeley Laboratory \\ 1 Cyclotron Road \\ Berkeley, CA 94720
}

\section{Abress}

This paper is concerned with the synchrotron radiation from an undulating electron beam in a rectangular waveguide. It is shown analyocally and numarically that tho rediated energy spectum may differ significandy from the free space result when the undulator length divided by the Lorentz factor of the electron beam is larger than the transverse size of the waveguide. The undulator rediation is identified with the wake field in beam instabilities. The concepts of wake function and impedance are introduced to formulate the present problem in the same manner as the beam instability problem. It is shown that the obtained impedances satisfy the Panofsky-Wenzel theorem and other properies inevituble for wake fields.

\section{Introduction}

An (planer) undulator is a device to produce a high-flux quasi-monocturomatic redietion in nerrow angular cone in the forwerd direction. Most of worke on the undulator refer to rediation in free space. In reality, however, undulators are surrounded by the metallic boundaries such as vacuum chamber. Then, the first question arices:

Ilow will the properties of the undulator radiation be changed when the boundaries are vaken into account?

The radiation in the waveguide can be identified to the excitarion of the waveguide modes. The radiated energy is redistribuled among matched waveguide modes. In a consequence, the energy spectrum tends to be changed from the monotonously increasing function to discrete sharp peaks, each corresponding to an excited waveguide mode. This change is particularly of interest in the low frequency region where the redistribution of the radialed energy into small number of modes will enhence hight of their spectra significanly. If the wavelength of those waveguide modes is larger than the bunch size. the whole bunch is rein[orced to move together by the waveguide fields. This may eause a new type of collective instability. So far, oniy few works have been done on the influence of metallic boundaries on the radiation [1]-[3]. In the reference [3], the author presents a general method to calculate the radiation fields from an undulstor with finice length in the presence of rectangular waveguide. In this paper, we show only the final results of the analysis. The method is actually the generalization of MotzNakamura i Hervian vector method.

\section{Once the fields are calculuted, the next question arises:}

Ilow will the radiation fields disturb the motion of particles in a beam?

In this question, both the high ano the low frequency parts of the rediation play important roles. The high frequency part will contribute to the bunching of particles in a mictoseopic scale. which induces the coherent radistion Irom particles in the same bunch. This is the stimulated emission process in FEL's. The low frequency part if it contuins significant energy, will drive collective motion of the whole bunch. In bolh cases, the partieles and the radiation fields crente a interactive system Our ultimate purpose is to solve this particles-radiation system in a self-consistent way. For this end. it is necessary at first to formulate the action of the undulator radiation fields on particles. We have a similar situntion in beam instability problems [4]. A charged particle interacts with its environment in create a wake field. This field acts back on the bean and disturbs the particle motion. This particles-environment system may be identified with the present particles-radiation system. If this identification is possible, we should better formulate the present problem in the same manner as beam insubility problem, so that we can apply all the techniques aceumulated in the beam instability study. With this in mind, we introduce the concepts of wake functions and their Fourier transforms, impedance.

\section{Radiation Spocioum}

The geometry of concern may be that a part of a considerably long waveguide is andwiched by the undulator for the finite length. Wo assume that the walls have infinite conductivity. We denote the inside region of the waveguide by $0 \leq x \leq a$ and $0 \leq y \leq b$. We consider a single electron moving in $x-z$ plane. It enters to the undulator at $x=x_{0}, y=y_{0}, z=z_{0}$ at ime $t=0$. The andulator hes length $L$. The totil radiated energy $U$ is given by [3]

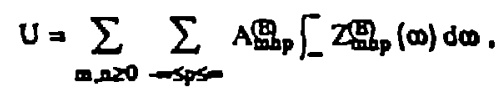

where

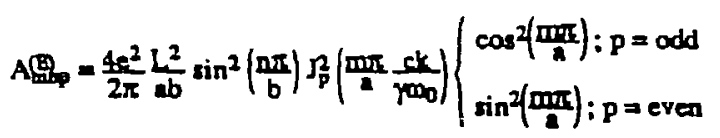

and

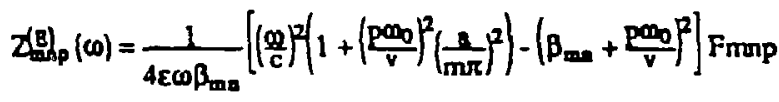

$$
\begin{aligned}
& \text { with Fmnp }=\frac{\sin ^{2}\left(\beta_{p}-\beta_{m a}\right) L \Omega}{\left(\left(\beta_{p}-\beta_{m a}\right) L \Omega\right)^{2}} \text {. }
\end{aligned}
$$

where $J_{p}(x)$ is the Bessel function. Other notations are as follows: $k=e B /\left(\right.$ mcko). $B$ is the undulator field, $w_{\alpha}(=(k a / v)$ is the undulata frequency, $\gamma$ is the Lorente fector of the electron, $m$ is the electron rest mass, $v$ is the initial longitudinal velocity of the electron, $c$ is the speed of light, $e$ is the unit charge, and $\varepsilon$ is the dielectric constant The quanity $A_{\text {mnp }}^{(E)}$ depends on the particle orbit and provides the selection rule about mode number: $n=$ odd, $m+p=$ odd. On the other hand, the quantity $Z_{\text {map }}^{(E)}(\infty)$ has the ame dimension as impedance The product $A_{\text {mip }}^{(D)} Z_{\text {mip }}^{(D)}(D)$ represents the energy llow of the radiation of the p-th hamoric from the undulated electron into the waveguide mode specified by $(m, n)$. Note that $Z_{\text {map }}^{(B)}(\infty)$ is alwaya positive and is an even function of $\omega$ being accompanied with the change in sign of $p$, t.e., $Z_{\text {mnp }}^{(E)}(\infty)=Z_{m n-p}^{(E)}(-\infty) \geq 0$.

The quantity $\widetilde{U}_{t}$ is defined by the energy spectrum for $p=1$ nommlized by its pesik value a $\omega=20 \mathrm{~m}^{2}$ in free space radiation:

$$
\overline{\mathrm{U}}_{\omega}=\frac{d \mathrm{U}}{\mathrm{d \omega}} /\left(\frac{\mathrm{e}^{2} \mathrm{Nk}^{2}}{4 \epsilon c}\right) \text {. }
$$

It is found that $\tilde{U}_{0}$ can be chancterized by the four perameters only: $\gamma_{1} N=$ the number of undulator periods, $\lambda_{0}=$ the undulator walelength, and the normalized waveguide transverse sizes $A=$ s $\gamma / \lambda_{0}$ and $B=b \gamma / \lambda_{0}$. Figures $1(a)$ and $(b)$ show some numerical examples of $\tilde{U}_{-}$. The free space spectre denoted by the broken lines are drawn for comparison. The parameters $\gamma=2935.42, N=98, \lambda_{0}$ a $5 \mathrm{~cm}$ are relevant to those of US.0 at the Advanced Light Source (ALS) of LBL[S]. The regular transverse vizes of the waveguide at

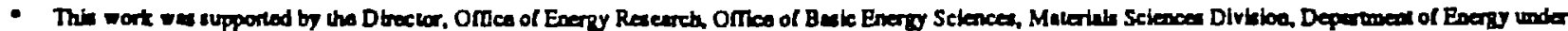
Coatenet Na. DEAC03-765F00098. 
ALS are approximately $a=12 \mathrm{~cm}$ and $b=2 \mathrm{~cm}$. They are about 10 imes larget than those in Fig. I(b) for both directions. One can seo that for small values of $A$ and $B$ like Fig. I( $\Delta$ ) (alchough they aro unrealistically small), a substantial power goes into a small number of waveguide modes, each of them corresponding to the peak. Ilowever. for large values of $A$ and $B$, the spectrum is smoothed out and approsches the free space result. In fact, we can prove andyocally that both spectra agree with each other in the limit of infinitely large structure $A, \vec{B}, N \rightarrow \infty$.

From Figs. 1(a)-(b), we can derive the following empirical criterion for the transverse size of the waveguide in which the boundary effects may be neglocted (we assume always a $\geq$ b):

$$
b \geq L N
$$

The eriterion(5) can be derived also from the following physical consideration. In the electron rest frame, the length of the undulator is LY. If the radision emitred at the entrance of the undulata into the purcly vertical direction cannot come back to the electron after bouncing at the boundary by the time when the electron gets out of the undulator. the boundery effects cannot influence the interaction properties berween the electron and the ratiation fields. It takes time $b / c$ This value has wo be larger then $L /(y)$.

The anergy spectrum in the yery low frequency region from 0 to $30 \mathrm{GHz}$ shows thrt their heights stry up $1010^{-4}$ of the penk value of the free radiation. They might be too imall to excite any serious collective motion of the beam.
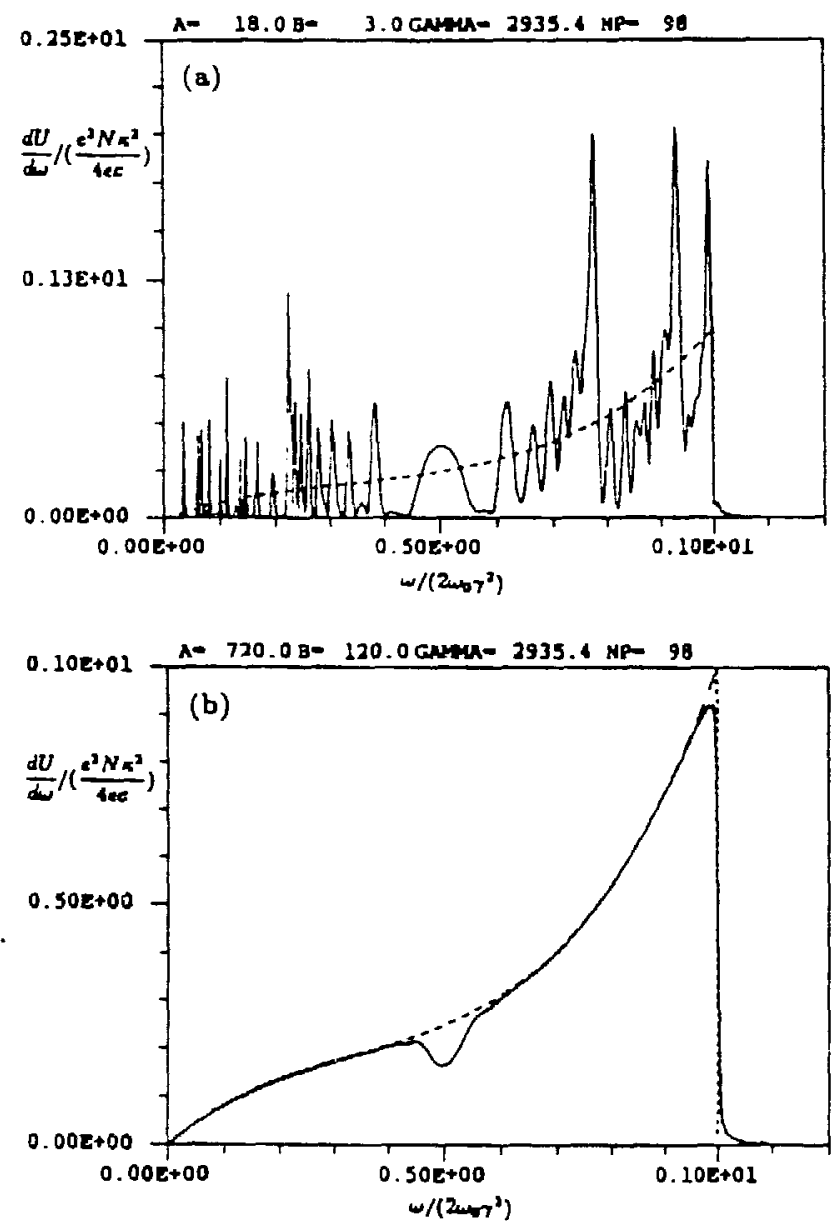

Fig. 1 Rediered energy rpectra (a) for $a=400 \mu \mathrm{m}$ and $b=67 \mu \mathrm{m}$, (b) for $a=12 \mathrm{~mm}$ and $b=2 \mathrm{~mm}$. The free space results are denoled by the broken lines.

\section{Wake Function and لmondance}

We here would like to study the action of the radiation on perticles in a beam If we are allowed to neglect the perturbation in particle motions due to the radistion fields while purticles go through the undulator, we can apply the concepts of wake function and its Fourier transform, impedance[4]. Suppose a charged particle travelling through an undulator, emiting the radiation. We call it the driving particle Imagine another particle (lest particle) which moves together with the driving particle kexping the fixed distance $Z=T$ v. The wate function is defined by the woul Lorent force exered on the test perticle over the suructure from the radiation fields. The test perticle may go either ahead of or behind the driving particle. In the definition of the longitudinal wake function $W_{2}(T)$, we need the minus sign in front of the Lorentz force. This follows the convention of the beam instability formalism where $W_{2}(T)$ is al ways negative, i.e. the test particle is decelerated, in the vicinity of the driving perticle If the test parricle is the same particle as the driving one $(r=$ O), the longindinal wake function gives the energy loss of the perticle due to deceleration by the fields created by itself. This energy loss is nothing but the toul radiated energy, namely, $W_{2}(0)=$ U.

After ledious calculation, we obtain.

$$
W_{v}(T)=\sum_{m \sum 20} \sum_{-s p s p} A_{\text {mopp }} W_{\text {mopv }}(T)
$$

with

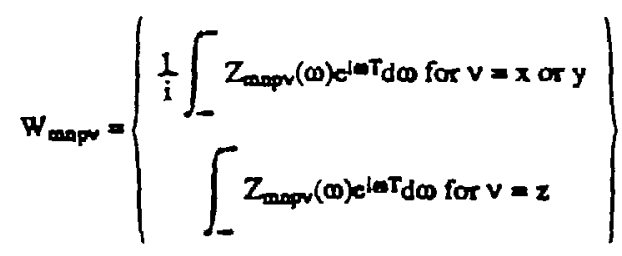

where

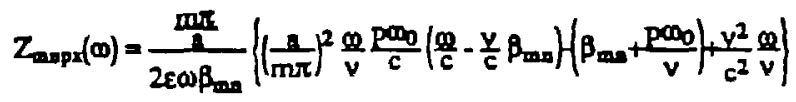

$$
\begin{aligned}
& \text { - Fmnp }
\end{aligned}
$$

$Z_{m a p s}(\infty)=\frac{\frac{n \pi}{b}}{2 \varepsilon \omega \beta_{m n}}\left\{\left(\frac{a}{m \pi}\right)^{2} \frac{\varphi}{v}\left(\frac{p m_{0}}{c}\right)^{2} \cdot\left(\beta_{m n}+\frac{p m_{0}}{v}\right)+\frac{v^{2}}{c^{2}} \frac{m}{v}\right\}$

$$
\text { - Fmnp }
$$

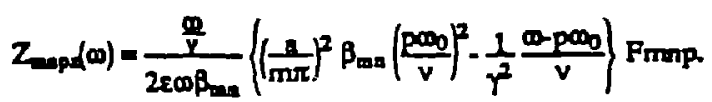

The explicit forms of Amopr's for $p=$ add we an follows:

$$
\begin{aligned}
& A_{\text {mom }}=\frac{x^{2}}{2 \pi} \frac{d L^{2}}{b} \cos \left(\frac{m \pi}{a} x_{0}\right) \sin \left(\frac{m \pi}{a} x_{1}\right) \\
& \left.\sin \left(\frac{n \pi}{b} y_{0}\right) \sin \left(\frac{n \pi}{b} y_{1}\right)\right\} \frac{2}{p}\left(\frac{m \pi}{a} \frac{c k}{\gamma m_{0}}\right) \text {. }
\end{aligned}
$$

$$
\begin{aligned}
& A_{\text {mapy }}=\frac{e^{2}}{2 \pi} \frac{4 L^{2}}{b} \cos \left(\frac{m \pi}{a} x_{0}\right) \cos \left(\frac{m \pi}{\pi} x_{1}\right) \\
& \left.\left.\sin \left(\frac{\pi \pi}{b} y_{0}\right) \cos \left(\frac{n \pi}{b} y_{1}\right)\right\} \frac{2(m \pi}{a} \frac{c k}{\gamma_{0}}\right) \text {. }
\end{aligned}
$$

$A_{\text {map } 2}=\frac{c^{2}}{2 \pi} \frac{4 l^{2}}{b} \cos \left(\frac{m \pi x}{a} x_{0}\right) \cos \left(\frac{m \pi}{a} \pi_{1}\right)$ 


$$
\sin \left(\frac{n \pi}{b} y_{0}\right) \sin \left(\frac{a \pi}{b} y_{1}\right) \frac{2}{2}\left(\frac{m \pi}{2} \frac{c k}{\gamma \omega_{0}}\right)
$$
(13)

Some conelusions may bo from inspection of Eqs. (6) to

(1) The transverse impedances are odd funcions of froquency $\omega$ in connection with the change in sign of $p: Z_{\operatorname{mop}}(\infty)=$ $-Z_{\text {onn.pv }}(-\infty) \geq 0$ for $v=x$ or $y$, while the longitudinal impedenco is an even function of $\omega$ : $Z_{\text {mopr }}(\Phi)=Z_{\text {mn,-pz }}(-\omega) \geq 0$. This concludes that $W_{\text {mop }}(0)=0$ for $v=\mathrm{x}$ or $y$ which means that a parricle receives no not transverse force from the radiation created by itself.

(2) If we cake the limit of infinitely long waveguido, we can find that the following relationstips hold between the transverse and tho longitudinal impedances for the seme set of (mn,p)

$$
\begin{aligned}
& Z_{\text {mapd }}(\omega)=\frac{\omega-p \omega_{0}}{v}\left(\frac{\alpha}{m \pi}\right) Z_{\text {mapx }}(\omega) . \\
& Z_{\text {mmp }}(\omega)=\frac{\omega-p \omega_{0}}{v}\left(\frac{b}{n \pi}\right) Z_{\text {mapy }}(\omega) .
\end{aligned}
$$

The above relationships are quite similas to the Panofsty-Wenzel theorem except for the factor $\left(\omega-p_{0}\right) \mathrm{v}$ instead of $\omega / v$. The appearance of $\mathrm{p} \omega_{0} / \mathrm{v}$ might originace $w$ the characteristics of the undulated atrit of the paricle

(3) From Eqs. (11)-(13) and (6). we notice the

$$
W_{x}(T)=0 \text { if } x_{0}=x_{1}=\frac{k}{2} \text {, and } W_{X}(T)=0 \text { if } y_{0}=y_{1}=\frac{b}{2} \text {. }
$$

This is abvious from the geometrical symunetry of the perticle trajectory and the waveguide.

In carrying out the integration in Eq. (7). it is necessary to separate the frequency range of the integration in impedance uccording to the sign of T. Namely, the test particle lagging behind or going thend of the driving particle sees different frequency range of the impedance. There is the following physieal reason for this case distinction. For simplicity, let us consider the radietion in free space. In the electron rest frame, the power flow to the rediation must be the same in the forward and the backward directions for symmetry. Most parts of the backward radiation in the electron rest frame are turned afound into the forward direction in the laborntory frame by the Lorente tranformation. The plane $z^{\prime}=0$ perpenticular to the $z^{\prime}$-exis in the electron reat frume forms a namow cone about the 2 -axis with the angle $\theta=L / \gamma$ in the laboratory frame. The one inside and outside of the cone correspond to the forward and the backward radiations in the electron rest frame. respectively. The test particle lagging behind the driving particle in the laboratory frame is also sitting behind it in the electron rest frame. Therefore it can feel only the backward radiation in the reat freme. It sees the forward ndietion outside of the cone and the backward radiation in the laboralory frame. The test particle going abead of the driving particle sees the forward riation in the electron rest frume and the corresponding forwand radiation inside of the cone in the laboratory frame. The frequency of the ndiation fields emitted along the cone is $\omega_{\text {cose }}=$ proor ${ }^{2}$. From the above arguments, we can conclude that for $T>(<) 0$, i.e, when the leat particle lags behind (goes ahead of) the driving particle, the integral in Eq (7) should be done over the frequency range from $0\left(\mathrm{por}_{\mathrm{r}} \mathrm{r}^{2}\right)$ to $\mathrm{pow}^{2} \mathrm{r}^{2}(\infty)$.

Figure 2 is an example of the longitudinal wake functions. Again, the parameten are tuten from those of US.0 at ALS. One can see that the wake function is significant only in the very vicinity of the driving particle $\left(\Delta T-2 \pi /\left(\omega_{0} \gamma^{2}\right)\right)$. This is due to mpidly oscillatirg phase factor $e^{100 T}$ in the incegrand for a large $T$. The broten lines denole the wake function in free space radiation. Even for tho small value of the transverne sizes, no large difference in the wake functions are recognizable, although the eacrgy spectre are quite different (seo Figs. I(a))
If we compare Eqs. (1)(3) with Eqs.(6)-(13) and may neglect the quantities amaller then tho leading term by a fector $\gamma^{2}$, wo an reach thet

$$
\frac{1}{2}\left(W_{d}\left(0_{+}\right)+W_{d}\left(0_{-}\right)\right)=U=W_{d}(0)
$$

In fach the relutionship (17) is a physical consequence of the energy conservation and can bo derived from the following thinking experiment. Suppose that the test particle follows the driving particle at an in firitesimal disance and they have opposite unit charges. Here the lat purticlo is a real particle, i.e., it also emita the radiation. Both particles lose the energy $U$ to the radiacion, while the test and the driving particles gain the energy $W_{2}\left(0_{2}\right)$ and $W_{2}\left(0_{+}\right)$, respectively. from the fields radiated by other particle. When they aro put wgether, the chages will be acutralized and tho radiation is suppreseed. In onder for the toul energy to be conserved, wo need

$$
W_{\mathbf{z}}\left(\mathbf{a}_{\mathbf{4}}\right)+\mathrm{W}_{\mathbf{2}}\left(0_{-}\right)=2 \mathrm{U}
$$

which agrees with Eq.(17). The above relationship is the modified form of the fundational theorem of beam loading[4].

\section{Conclusions}

The identification of the undulator radiation with the wake field in beam instabilities seems to be all right. the obtained transverse and longitudinal impedances sariefy the Panoisky-Wenzel theorem. The difference is only that the wake function is significant mostly ahead of the driving particle in the undulator radietion, while it is non-zero only behind the driving perticle in wate fields. The longitudinal wake function includes nocesany information about how particles will be accelerated or decelerated by the rndiation fields. From this, one cen calculate the bunching of particles and eventually explain the stimulated emiusion process of FEL

\section{References}

[1] IL Motz and M. Nakamurn, Ann. Phys., 7, 84 (1959).

[2] A Amir, I. Boscola, and LR. Elia, Phys. Rev. A, 32, 2864 (1985).

[3] Y.H. Chin, LBL Repon to be published.

[4] A.W. Cheo, SLAC-PUB-2946 (1982).

[5] 1-2 GeV Symchrocon Reatiation Source Conceptual Design Repon - July 1896, LBL Report PUB-5172 Rev. (1986).

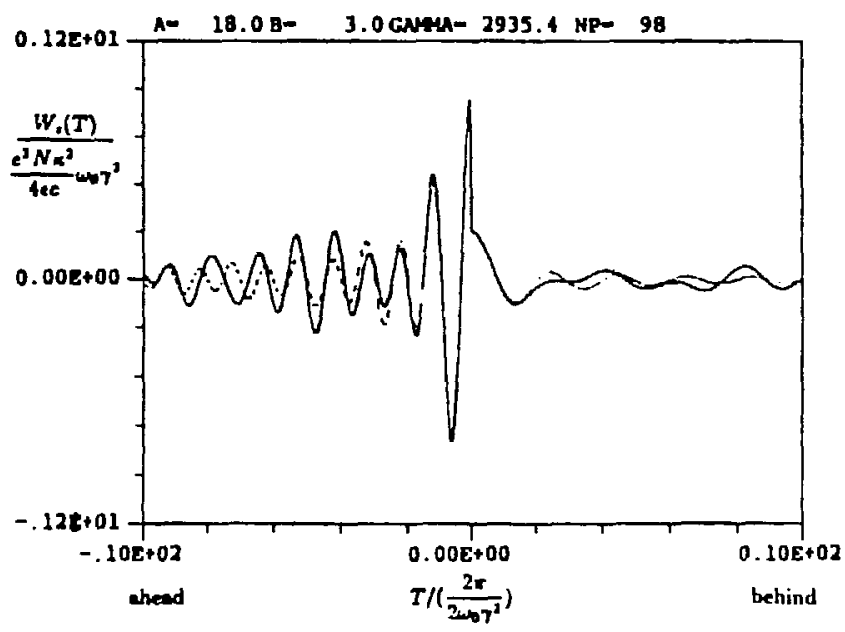

Fig. 2 Longindinal wake function for $a=400 \mu \mathrm{m}$ and $b=67 \mu \mathrm{m}$ The fro rpace renult is denoled by the broken lina. 